\title{
Asymptomatic Long-term Cardiac Perforation by a Pacemaker Lead
}

\author{
Tomoko Nakao ${ }^{1}$, Katsuhito Fujiu ${ }^{1,2}$, Masae Uehara ${ }^{1}$ and Issei Komuro ${ }^{1}$
}

Key words: complication, pacer, coronary sinus musculature

(Intern Med 58: 2409-2410, 2019)

(DOI: 10.2169/internalmedicine.1991-18)
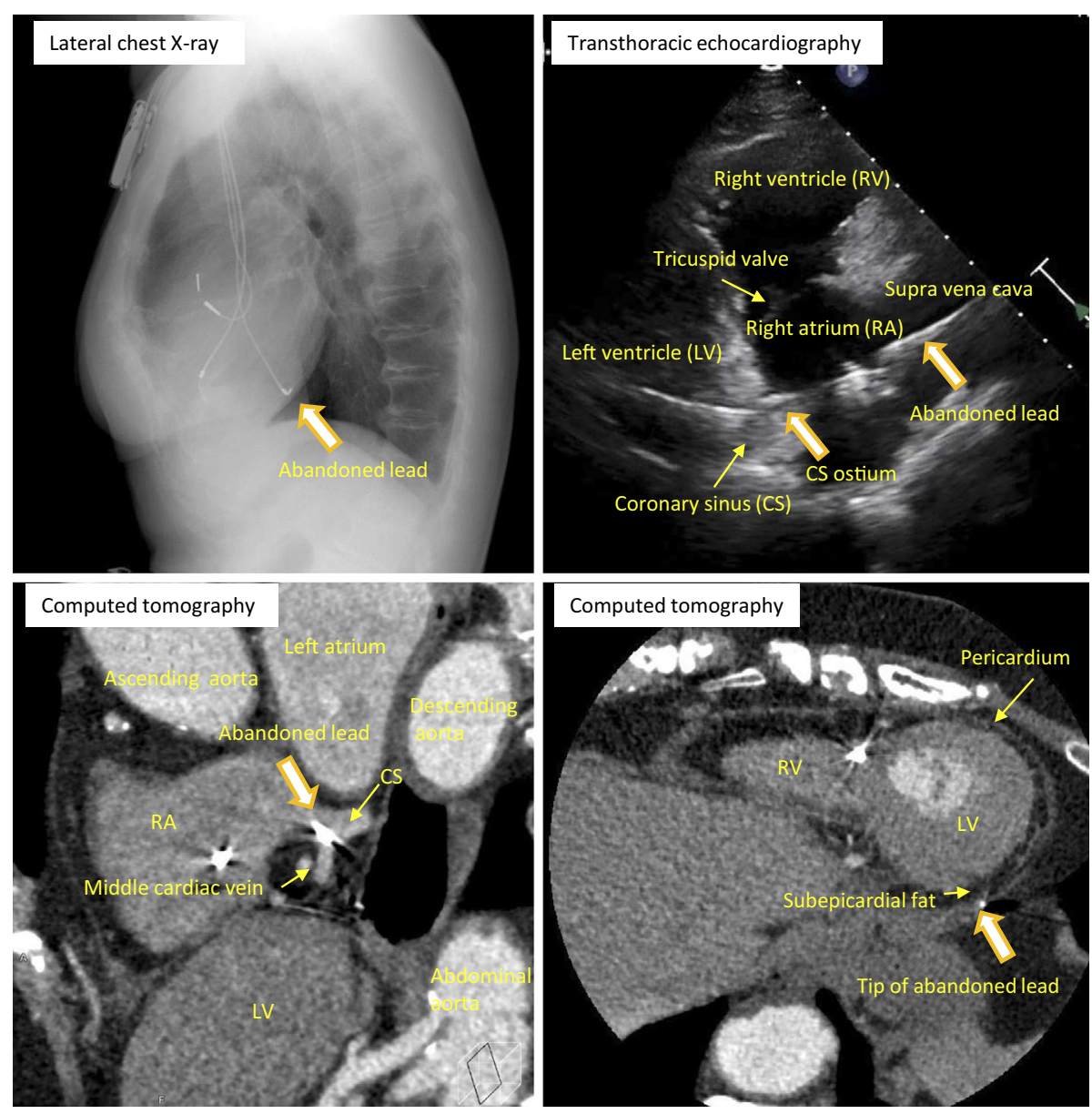

Picture.

A 92-year-old woman underwent DDD pacemaker implantation at 66 years of age, and a ventricular lead was added because of an increase in the ventricular lead pacing threshold 10 years later $(2 \mathrm{~V} / 0.5 \mathrm{~ms}$ at implantation and 3.9 $\mathrm{V} / 0.4 \mathrm{~ms}$ after 10 years). Lateral chest X-ray revealed the abnormal position of an abandoned lead. Transthoracic echocardiography and computed tomography showed that the lead pierced the coronary sinus (CS) ostium, with its tip located in the subepicardial fat around the left ventricle (Picture). Cardiac perforation by pacemaker leads is usually de-

${ }^{1}$ Department of Cardiovascular Medicine, The University of Tokyo, Japan and ${ }^{2}$ Department of Advanced Cardiology, The University of Tokyo, Japan

Received: August 19, 2018; Accepted: February 11, 2019; Advance Publication by J-STAGE: May 22, 2019

Correspondence to Dr. Katsuhito Fujiu, fujiu-tky@umin.ac.jp 
tected on the appearance of symptoms and requires surgical repair (1); however, in the only similar previous case we found, the patient reported no symptoms even after atrial perforation (2). Notably, the common denominator in the present and previous cases was a CS ostium covered by CS musculature at the lead's perforated site. In cases of pacemaker lead perforation at this location, issues might be masked for an extended period of time.

The authors state that they have no Conflict of Interest (COI).

\section{References}

1. deRoux SJ. Fatality following right atrial perforation by a screw-in pacemaker electrode. J Forensic Sci 50: 1191-1193, 2005.

2. Lees DA, Green GD. Long-term epicardial ventricular pacing from endocardial bipolar pacemaker lead: perforation of right atrial wall. Thorax 32: 370-372, 1977.

The Internal Medicine is an Open Access journal distributed under the Creative Commons Attribution-NonCommercial-NoDerivatives 4.0 International License. To view the details of this license, please visit (https://creativecommons.org/licenses/ by-nc-nd/4.0/).

(C) 2019 The Japanese Society of Internal Medicine Intern Med 58: 2409-2410, 2019 